\title{
Distribution characteristics and influencing factors of homocyteine in an apparently healthy examined population
}

Fang Bao ${ }^{1}$, Ming Cui ${ }^{1}$, Xiuying Shi ${ }^{1}$, Shaoqing Ju ${ }^{1}$ and Hui Cong ${ }^{1,2^{*}}$ (D)

\begin{abstract}
Background: Homocysteine (Hcy) is considered to be a risk factor for cardiovascular and cerebrovascular diseases. Few studies have evaluated the distribution of Hcy on a large-scale health examination. Accordingly, this study aimed to investigate the level and distribution of Hcy in the population with healthy physical examination and the correlation with other biomarkers, and analyzed for cardiovascular and other diseases.

Methods: Measurements of serum Hcy, TC, TG, LDL-C, HDL-C, ALT, ALP, Y-GT, TBIL, GLU, urea, Cr, UA, and related metabolic risk factors were selected for analysis from 8063 medical examination samples collected from February 2017 to April 2020. The relationship between Hcy and other biochemical indicators were evaluated with the multivariate regression model of age, gender, smoking, drinking, body mass index (BMI), systolic blood pressure (SBP), and diastolic blood pressure (DBP).

Results: Among 8063 cases, the age, BMI, SBP, and DBP of the high-Hcy group were higher than those of the lowHcy group, the difference was statistically significant $(P<0.001)$, and the proportion of males, smoking, and drinking were higher than the low-Hcy group, the difference was statistically significant $(P<0.001)$; Hcy of the abnormal GLU group is higher than the normal GLU group $(P=0.002)$ and the Hcy of abnormal TG and HDL is higher than that of the normal blood lipid group $(P<0.001)$; Hcy of people with abnormal UA and Urea was higher than that of people with normal renal function $(P<0.001, P=0.007)$. In multivariate analysis, InHDL-C was negatively correlated with InHcy $(\beta=-0.038, S E=0.016, P=0.019)$, InCr was positively correlated with InHcy $(\beta=0.055, \mathrm{SE}=0.016, P<0.001)$, InUA and InHcy were positive correlated $(\beta=0.043, \mathrm{SE}=0.019, P=0.022)$.
\end{abstract}

Conclusion: $\mathrm{Hcy}$ is closely related to $\mathrm{HDL}-\mathrm{c}, \mathrm{Cr}$, and $\mathrm{UA}$, which indicates that Hcy may affect the metabolism of HDL-c and $U A$, and can also be used as an auxiliary diagnostic index for kidney injury.

Keywords: Homocysteine, Creatinine, Uric acid, High-density lipoprotein cholesterol

\section{Background}

Homocysteine (Hcy) is a sulfur-containing amino acid produced during the metabolism of methionine in cells of the body which involves folic acid and vitamin B12. Its pathogenic mechanism includes vascular endothelial

\footnotetext{
*Correspondence: huicjs@163.com

1 Department of Laboratory Medicine, Affiliated Hospital of Nantong University, Nantong 226001, China

Full list of author information is available at the end of the article
}

damage, stimulating smooth muscle cell proliferation, affecting coagulation and thrombus activation, etc. The elevation of Hcy is considered an independent risk factor for cardiovascular and cerebrovascular diseases $[1,2]$. In this paper, we report the level and distribution characteristics of Hcy and their correlation between other biochemical indicators by analyzing a population of 8063 medical examination results, as well as the possible 
influencing factor for cardiovascular and cerebrovascular diseases.

\section{Methods}

The subjects of this study came from a total of 8063 cases of the physical examination population in our hospital from February 2017 to April 2020. Inclusion criteria: (1) Daily physical fitness; (2) No acute or chronic infections, tumors or rheumatic diseases were found after clinical examination. Exclusion criteria: (1) Recent use of drugs affecting blood Hcy level and blood lipid level; (2) Subjects with severe liver and kidney insufficiency, anemia, and cardiac insufficiency; (3) Genetic metabolic diseases, malignant tumors, connective tissue diseases, etc. This research protocol was approved by the Ethics Committee of Nantong University Affiliated Hospital. The distribution characteristics of Hcy, blood lipids and other biochemical indicators, systolic blood pressure (SBP), diastolic blood pressure (DBP), body mass index (BMI), and pulse of the physical examination population were observed. The subjects were stratified according to gender and Hcy in low $(\mathrm{Hcy} \leq 15 \mu \mathrm{mol} / \mathrm{L})$ and high $(\mathrm{Hcy}>15 \mu \mathrm{mol} / \mathrm{L}) \mathrm{Hcy}$ group. Other indicators are divided into normal group and abnormal group according to the literature [3-10].

$5 \mathrm{~mL}$ of venous blood was collected from subjects fasted for $12 \mathrm{~h}$ into a vacuum test tube containing separation gel. After the blood coagulated, the serum was separated by centrifugation at $2062 g$ for 10 min within $2 \mathrm{~h}$ and tested on the machine. All tests were carried out with the internal quality control when the instrument and reagents were in normal condition, and were carried out in strict accordance with the reagent and instrument standard operating procedures (SOP). All biochemical indexes measured on Beckman-Coulter AU5800 automatic analyzer. Hcy (enzyme cycling method) kit (LOT: 0200103) and calibrator were purchased from Qiangsheng Biotechnology Co., Ltd., quality control products were provided by Shanghai Kunlai Biotechnology Company; ALT (lactate dehydrogenase method), ALP (NPP substrate-AMP buffer method)), $\gamma$-GT (rate method), TBIL (diazonium method), TG (GPO-POD method), TC (cholesterol oxidase method), LDL-c (direct method), HDL-c (direct method), GLU (hexokinase method), BUN (urease-glutamate dehydrogenase method), $\mathrm{Cr}$ (sarcosine oxidase method), UA (uricase-peroxidase method) are tested by Beckman-Coulter Original kits and calibrators, quality control products are provided by Bio-Rad.

\section{Statistical analysis}

Statistical software stata 20.0 was used for data analysis, skewness and kurtosis normality test (sktest). Numerical variables of the normal distribution were expressed by the mean \pm standard deviation, and the comparison between two groups was performed by the $\mathrm{T}$ test; the median (interquartile range) was used to express numerical variables of the non-normal distribution, and the Mann-Whitney U test was used for comparison between the two groups. Kruskal-Wallis test was used for comparison among multiple groups. The qualitative data were all expressed by the number of cases (percentage), and the chi-square test was used for comparison between groups. This study analyzed the relationship between Hcy and TC, TG, LDL-c, HDL-c, ALT, ALP, TBIL, $\gamma$-GT, Urea, $\mathrm{Cr}$ and UA through single factor, multivariate linear regression and logistic regression models. The skewed numerical variables were analyzed after natural logarithmic transformation, and the multivariate regression was adjusted for age, gender, smoking, drinking, pulse, and BMI. $P<0.05$ was considered statistically significant.

\section{Results}

\section{General characteristics}

This study included 8063 subjects with an average age of $(50.88 \pm 11.92)$ years old, BMI $(25.02 \pm 3.39) \mathrm{kg} / \mathrm{m}^{2}$, SBP $(130.54 \pm 18.85) \mathrm{mmHg}$, DBP $(78.66 \pm 11.96) \mathrm{mmHg}$, pulse $(77.54 \pm 11.31)$ times/min. Among them, 5478 cases were male, accounting for $67.94 \%$, and 2585 cases were female, accounting for $32.06 \%$, All subjects were aged between 20 and 79 years old. The BMI, SBP, DBP, and glucose of men were higher than women, and the difference was statistically significant $(P<0.001)$, while the pulse rate of men was lower than that of women with a statistically significant difference $(P<0.001)$. Among men, the proportion of smoking was $23.95 \%$ and the proportion of drinking was $64.8 \%$, which were much higher than those of women. Male ALT, $\gamma$-GT, TBIL, TG, LDL-c, Urea, $\mathrm{Cr}$, UA were all higher than females, and the difference was statistically significant $(P<0.001)$. TC, HDL-C were lower than females $(P<0.001)$, and there was no statistical difference in ALP between the two groups $(P=0.054)$, Table 1 .

\section{Comparison of Hcy between different groups}

Table 2 shows the comparison of Hcy among different groups. Hcy of males are higher than that of females $(P<0.001)$, Hcy of smokers and drinkers are higher than the control group $(P<0.001)$, Hcy of the overweight and obese groups are higher than the thin and normal BMI groups. $(P<0.001)$, Hcy of the abnormal blood pressure group is higher than the normal hypertension group $(P<0.001)$, Hcy of the abnormal GLU group is higher than the normal GLU group $(P=0.002)$ and the Hcy of abnormal TG and HDL is higher than that of the normal blood lipid group $(P<0.001)$; Hcy of people with 
Table 1 Distribution characteristics of the study population grouped by gender

\begin{tabular}{|c|c|c|c|c|}
\hline & Total $(n=8063)$ & Male $(n=5478)$ & Female $(n=2585)$ & $P$ \\
\hline Age (year-old), mean $\pm S D$ & $50.88 \pm 11.92$ & $49.98 \pm 11.49$ & $52.87 \pm 12.59$ & $<0.001$ \\
\hline $\mathrm{BMI}\left(\mathrm{kg} / \mathrm{m}^{2}\right)$, mean $\pm \mathrm{SD}$ & $25.02 \pm 3.39$ & $25.54 \pm 3.22$ & $23.91 \pm 3.48$ & $<0.001$ \\
\hline $\mathrm{SBP}(\mathrm{mmHg})$, mean $\pm \mathrm{SD}$ & $130.54 \pm 18.85$ & $131.49 \pm 17.28$ & $128.52 \pm 21.68$ & $<0.001$ \\
\hline $\mathrm{DBP}(\mathrm{mmHg})$, mean $\pm \mathrm{SD}$ & $78.66 \pm 11.96$ & $81.13 \pm 11.46$ & $73.43 \pm 11.30$ & $<0.001$ \\
\hline Pulse (bpm), mean $\pm S D$ & $77.54 \pm 11.31$ & $76.77 \pm 11.18$ & $79.19 \pm 11.42$ & $<0.001$ \\
\hline Smoking status, N (\%) & & & & $<0.001$ \\
\hline Current and former & $1312(16.27)$ & $1312(23.95)$ & $0(0.00)$ & \\
\hline Never & $6751(83.73)$ & $4166(76.05)$ & $2585(100)$ & \\
\hline Alcohol dringking, N (\%) & & & & $<0.001$ \\
\hline Current and former & $1930(23.94)$ & $1928(35.20)$ & $2(0.08)$ & \\
\hline Never & $6133(76.06)$ & $3550(64.80)$ & $2583(99.92)$ & \\
\hline $\operatorname{Hcy}(\mu \mathrm{mol} / \mathrm{L}), \mathrm{M}_{(\mathrm{P} 25-\mathrm{P} 75)}$ & $10.2(8.3-12.8)$ & $10.9(9-13.8)$ & $8.6(7.1-10.7)$ & $<0.001$ \\
\hline $\operatorname{ALT}(U / L), M_{(P 25-P 75)}$ & $24(18-34)$ & $26.5(20-38)$ & $19(15-26)$ & $<0.001$ \\
\hline$A L P(U / L), M_{(P 25-P 75)}$ & $81(67-96)$ & $81(69-95)$ & $80(65-98)$ & 0.054 \\
\hline Y-GT (U/L), $\mathrm{M}_{(\mathrm{P} 25-\mathrm{P} 75)}$ & $28(19-45)$ & $33(23-53)$ & $18(14-27)$ & $<0.001$ \\
\hline TBIL $(\mu \mathrm{mol} / \mathrm{L}), \mathrm{M}_{(\mathrm{P} 25-\mathrm{P} 75)}$ & $13.7(10.8-17.3)$ & $14.4(11.6-18.1)$ & $12(9.6-15.1)$ & $<0.001$ \\
\hline GLU (mmol/L), $\mathrm{M}_{(\mathrm{P} 25-\mathrm{P} 75)}$ & $5.3(4.9-5.8)$ & $5.3(5-5.8)$ & $5.2(4.9-5.6)$ & $<0.001$ \\
\hline $\mathrm{TC}(\mathrm{mmol} / \mathrm{L}), \mathrm{M}_{(\mathrm{P} 25-\mathrm{P} 75)}$ & $5.1(4.5-5.8)$ & $5.1(4.5-5.7)$ & $5.2(4.6-5.8)$ & $<0.001$ \\
\hline TG $(\mathrm{mmol} / \mathrm{L}), \mathrm{M}_{(\mathrm{P} 25-\mathrm{P} 75)}$ & $1.4(0.95-2.1)$ & $1.54(1.05-2.32)$ & $1.14(0.81-1.67)$ & $<0.001$ \\
\hline HDL-C (mmol/L), $M_{(P 25-P 75)}$ & $1.27(1.09-1.49)$ & $1.2(1.05-1.39)$ & $1.44(1.24-1.67)$ & $<0.001$ \\
\hline LDL-c (mmol/L), $\mathrm{M}_{(\mathrm{P} 25-\mathrm{P} 75)}$ & $3.06(2.54-3.57)$ & $3.07(2.56-3.59)$ & $3.01(2.51-3.53)$ & 0.013 \\
\hline Urea (mmol/L), $\mathrm{M}_{(\mathrm{P} 25-\mathrm{P} 75)}$ & $5.3(4.5-6.1)$ & $5.4(4.6-6.3)$ & $5(4.1-5.9)$ & $<0.001$ \\
\hline $\mathrm{Cr}(\mu \mathrm{mol} / \mathrm{L}), \mathrm{M}_{(\mathrm{P} 25-\mathrm{P} 75)}$ & $67(57-76)$ & $72(66-80)$ & $53(48-59)$ & $<0.001$ \\
\hline UA ( $\mu \mathrm{mol} / \mathrm{L}), \mathrm{M}_{(\mathrm{P} 25-\mathrm{P} 75)}$ & $332(269-393)$ & $363(313-416)$ & $256(218-304)$ & $<0.001$ \\
\hline
\end{tabular}

abnormal UA and Urea was higher than that of people with normal renal function $(P<0.001, P=0.007)$.

Regardless of gender, Hcy was higher in the group with abnormal TG V UA and BP than in the group with normal $(P<0.001)$; According to gender stratification, the Hcy of male abnormal GLU group was lower than that of normal GLU group $(P=0.035)$, and the Hcy of female abnormal GLU group was higher than that of normal GLU group $(P<0.001)$. In addition, Hcy of men with abnormal ALT was lower than that of normal ALT $(P=0.039)$, and Hcy of men with abnormal TBIL was higher than that of normal TBIL $(P<0.001)$; Hcy in overweight and obese women was higher than that in lean and normal BMI groups $(P<0.001)$, and Hcy in group with abnormal TC and HDL was higher than that in normal population $(P<0.001,0.027)$.

\section{Comparison of high and low Hcy indicators by gender}

Among men, the age, SBP, DBP, Cr and UA of the highHcy group were higher than those of the low-Hcy group, $P<0.001$. The GLU, between the high-Hcy group was lower than that of the low-Hcy group, $P<0.001$; the $\gamma$-GT, TBIL and TG of the high-Hcy group were higher than those of the low-Hcy group $(P=0.023,<0.001,0.011)$.
Among women, the age, BMI, SBP, and DBP of the high-Hcy group were significantly higher than those of the low-Hcy group. The ALP of the high-Hcy group was higher than that of the low-Hcy group, $P=0.001$. The TG of the high-Hcy group was significantly higher than that of the low-Hcy group, $P=0.003$, while the HDL-C was lower than the low-Hcy group, $P=0.005$; Both $\mathrm{Cr}$ and UA were significantly higher than the low-Hcy group, $P<0.001$. See Table 3 for details.

\section{Linear regression model analysis of the effect of serum Hcy level on blood lipid level}

As shown in Table 4, the single factor linear regression model analysis results show that lnHcy is negatively correlated with lnHDL-c, and lnHcy is positively correlated with $\ln$ TG, $\ln$ ALT, $\ln A L P, \ln \gamma-G T, \operatorname{lnTBIL}, \ln \mathrm{U}$ rea, $\ln C r$, and $\ln U A$. The adjusted multivariate linear regression model analysis of gender, age, BMI, smoking and drinking showed that InTG was positively correlated with $\operatorname{lnHcy}(\beta=0.080, \mathrm{SE}=0.021, P<0.001)$, and $\operatorname{lnHDL}-\mathrm{c}$ was negatively correlated with $\operatorname{lnHcy}$ $(\beta=-0.021, \mathrm{SE}=0.008, P=0.011), \ln \mathrm{ALT}$ was negatively correlated with $\ln H c y(\beta=-0.053, \mathrm{SE}=0.018$, $P=0.003$ ), and InTBIL was positively correlated with 
Table 2 Comparison of Hcy between different groups

\begin{tabular}{|c|c|c|c|c|c|c|c|c|c|}
\hline \multirow{2}{*}{ 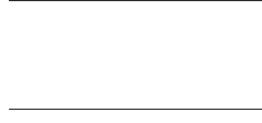 } & \multirow{2}{*}{ Hcy $(n=8063)$} & \multirow[t]{2}{*}{$\mathrm{Z} / \mathrm{H}$} & \multirow[t]{2}{*}{$P$} & \multicolumn{3}{|l|}{ Male } & \multicolumn{3}{|l|}{ Female } \\
\hline & & & & $\operatorname{Hcy}(n=5478)$ & $\mathrm{Z} / \mathrm{H}$ & $\mathbf{P}$ & $\operatorname{Hcy}(n=2585)$ & $\mathrm{Z} / \mathrm{H}$ & $\mathbf{P}$ \\
\hline Sex & & 30.910 & $<0.001$ & & - & - & & - & - \\
\hline Male & $10.9(9.0-13.8)$ & & & - & & & - & & \\
\hline Female & $8.6(7.1-10.7)$ & & & - & & & - & & \\
\hline Smoking status & & -8.896 & $<0.001$ & & 0.581 & 0.5610 & & - & - \\
\hline Current and former & $10.9(9.0-13.8)$ & & & $10.9(9.0-13.8)$ & & & - & & \\
\hline Never & $10.1(8.1-12.7)$ & & & $11.0(9.1-13.8)$ & & & $8.6(7.1-10.7)$ & & \\
\hline Alcohol drinking & & -11.048 & $<0.001$ & & 1.183 & 0.2368 & & 0.660 & 0.510 \\
\hline Current and former & $10.8(9.0-13.6)$ & & & $10.8(9.0-13.6)$ & & & $7.8(6.9-8.7)$ & & \\
\hline Never & $10.0(8.1-12.6)$ & & & $11.0(9.1-13.9)$ & & & $8.6(7.1-10.7)$ & & \\
\hline$B M I\left(\mathrm{~kg} / \mathrm{m}^{2}\right)$ & & 117.157 & $<0.001$ & & 4.565 & 0.2066 & & 32.569 & $<0.001$ \\
\hline Weight loss & $9.2(7.9-12.4)$ & & & $11.8(8.9-15.9)$ & & & $8.6(7.2-10.2)$ & & \\
\hline Normal & $9.7(7.9-12.2)$ & & & $10.7(8.9-13.6)$ & & & $8.4(7.0-10.4)$ & & \\
\hline Overweight & $10.5(8.5-13.2)$ & & & $11.1(9.1-13.8)$ & & & $8.7(7.1-10.9)$ & & \\
\hline Obesity & $10.6(8.7-13.5)$ & & & $10.8(9-13.95)$ & & & $9.5(7.9-11.5)$ & & \\
\hline Blood pressure $(\mathrm{mmHg})$ & & -12.666 & $<0.001$ & & -4.511 & $<0.0001$ & & -9.976 & $<0.001$ \\
\hline Normal & $9.6(7.8-12.2)$ & & & $10.7(8.8-13.4)$ & & & $8.2(6.8-10.0)$ & & \\
\hline Abnormal & $10.6(8.7-13.4)$ & & & $11.1(9.2-14.1)$ & & & $9.2(7.7-11.4)$ & & \\
\hline $\operatorname{ALT}(U / L)$ & & -0.004 & 0.997 & & 2.069 & 0.0386 & & 0.582 & 0.560 \\
\hline Normal & $10.2(8.3-12.8)$ & & & $11.0(9.1-13.9)$ & & & $8.6(7.2-10.7)$ & & \\
\hline Abnormal & $10.3(8.3-12.7)$ & & & $10.7(8.8-13.3)$ & & & $8.5(6.9-10.9)$ & & \\
\hline$A L P(U / L)$ & & 2.573 & 0.010 & & 1.676 & 0.0938 & & 0.349 & 0.728 \\
\hline Normal & $10.3(8.3-12.8)$ & & & $11.0(9.0-13.8)$ & & & $8.6(7.2-10.7)$ & & \\
\hline Abnormal & $9.6(8.0-12.4)$ & & & $10.5(8.8-13.7)$ & & & $8.55(7.0-10.9)$ & & \\
\hline$\gamma-G T(U / L)$ & & -5.507 & $<0.001$ & & -1.082 & 0.2792 & & -1.246 & 0.213 \\
\hline Normal & $10.1(8.2-12.7)$ & & & $10.9(9-13.7)$ & & & $8.6(7.1-10.6)$ & & \\
\hline Abnormal & $10.8(8.6-13.5)$ & & & $11.1(9-14.1)$ & & & $8.7(7.3-11.3)$ & & \\
\hline TBIL ( $\mu \mathrm{mol} / \mathrm{L})$ & & -7.236 & $<0.001$ & & -4.158 & $<0.0001$ & & -0.749 & 0.454 \\
\hline Normal & $10.1(8.2-12.7)$ & & & $10.9(9.0-13.7)$ & & & $8.6(7.2-10.7)$ & & \\
\hline Abnormal & $11.2(9.1-13.9)$ & & & $11.7(9.6-14.2)$ & & & $8.8(7.0-11.6)$ & & \\
\hline GLU (mmol/L) & & -3.109 & 0.002 & & 2.112 & 0.0347 & & -3.922 & $<0.001$ \\
\hline Normal & $10.2(8.2-12.8)$ & & & $11.0(9-13.8)$ & & & $8.6(7.1-10.6)$ & & \\
\hline Abnormal & $10.5(8.6-13.1)$ & & & $10.8(9-13.7)$ & & & $9.2(7.6-11.4)$ & & \\
\hline$T C(\mathrm{mmol} / \mathrm{L})$ & & -1.192 & 0.233 & & -1.222 & 0.2216 & & -3.506 & $<0.001$ \\
\hline Normal & $10.2(8.2-12.8)$ & & & $10.9(9.0-13.8)$ & & & $8.5(7.0-10.4)$ & & \\
\hline Abnormal & $10.2(8.3-12.9)$ & & & $11.1(9.1-13.8)$ & & & $8.8(7.3-11.0)$ & & \\
\hline TG $(\mathrm{mmol} / \mathrm{L})$ & & -9.402 & $<0.001$ & & -2.261 & 0.0237 & & -4.309 & $<0.001$ \\
\hline Normal & $10.0(8.0-12.5)$ & & & $10.9(9.0-13.6)$ & & & $8.5(7.0-10.6)$ & & \\
\hline Abnormal & $10.6(8.7-13.4)$ & & & $11.0(9.1-14.0)$ & & & $9.0(7.5-11.1)$ & & \\
\hline HDL (mmol/L) & & -5.308 & $<0.001$ & & 0.698 & 0.4855 & & 0.0274 & 0.027 \\
\hline Normal & $10.1(8.2-12.7)$ & & & $10.9(9.0-13.9)$ & & & $8.6(7.1-10.7)$ & & \\
\hline Abnormal & $10.7(8.7-13.4)$ & & & $10.9(8.9-13.5)$ & & & $8.8(7.7-12.1)$ & & \\
\hline LDL (mmol/L) & & -0.313 & 0.754 & & 1.086 & 0.2776 & & -0.879 & 0.380 \\
\hline Normal & $10.2(8.3-12.8)$ & & & $11.0(9.0-13.8)$ & & & $8.6(7.1-10.6)$ & & \\
\hline Abnormal & $10.2(8.3-12.8)$ & & & $10.8(9.0-13.7)$ & & & $8.7(7.2-10.9)$ & & \\
\hline Urea (mmol/L) & & -2.691 & 0.007 & & -1.822 & 0.068 & & -1.759 & 0.079 \\
\hline Normal & $10.2(8.3-12.8)$ & & & $10.9(9.0-13.8)$ & & & $8.6(7.1-10.6)$ & & \\
\hline Abnormal & $10.9(8.3-14.1)$ & & & $11.6(9.2-14.8)$ & & & $9.4(7.2-11.6)$ & & \\
\hline $\operatorname{Cr}(\mu \mathrm{mol} / \mathrm{L})$ & & 0.030 & 0.976 & & -0.188 & 0.851 & & 1.649 & 0.099 \\
\hline Normal & $10.2(8.3-12.8)$ & & & $10.9(9.0-13.8)$ & & & $8.7(7.2-10.7)$ & & \\
\hline Abnormal & $10.2(8.0-13.4)$ & & & $11.0(8.8-14.2)$ & & & $8.2(6.7-10.8)$ & & \\
\hline
\end{tabular}


Table 2 (continued)

\begin{tabular}{|c|c|c|c|c|c|c|c|c|c|}
\hline & \multirow[t]{2}{*}{ Hcy $(n=8063)$} & \multirow[t]{2}{*}{$\mathrm{Z} / \mathrm{H}$} & \multirow[t]{2}{*}{$\mathbf{P}$} & \multicolumn{3}{|l|}{ Male } & \multicolumn{3}{|l|}{ Female } \\
\hline & & & & $\operatorname{Hcy}(n=5478)$ & $\mathrm{Z} / \mathrm{H}$ & $\mathbf{P}$ & $\operatorname{Hcy}(n=2585)$ & $\mathrm{Z} / \mathrm{H}$ & $\mathbf{P}$ \\
\hline$\overline{U A}(\mu \mathrm{mol} / \mathrm{L})$ & & -13.132 & $<0.001$ & & -5.409 & $<0.001$ & & -.389 & $<0.001$ \\
\hline Normal & $10.0(8.1-12.5)$ & & & $10.8(8.9-13.6)$ & & & $8.5(7.0-10.5)$ & & \\
\hline Abnormal & $11.1(9.2-14.2)$ & & & $11.3(9.4-14.5)$ & & & $9.8(8.4-12.5)$ & & \\
\hline
\end{tabular}

A history of smoking or drinking was defined as abnormal smoking or drinking

Table 3 The characteristics of the population in the high and low Hcy groups are stratified by gender

\begin{tabular}{|c|c|c|c|c|c|c|}
\hline & \multicolumn{3}{|l|}{ Male } & \multicolumn{3}{|l|}{ Female } \\
\hline & Low Hcy $(n=4479)$ & High Hcy $(n=999)$ & $P$ & Low Hcy $(n=2479)$ & High Hcy $(n=106)$ & $P$ \\
\hline Age (year-old), mean $\pm S D$ & $49.66 \pm 11.16$ & $51.37 \pm 12.78$ & $<0.001$ & $52.42 \pm 12.50$ & $61.79 \pm 11.25$ & $<0.001$ \\
\hline BMI $\left(\mathrm{kg} / \mathrm{m}^{2}\right)$, mean $\pm \mathrm{SD}$ & $25.54 \pm 3.21$ & $25.55 \pm 3.28$ & 0.941 & $23.86 \pm 3.40$ & $25.14 \pm 4.88$ & $<0.001$ \\
\hline $\mathrm{SBP}(\mathrm{mmHg})$, mean $\pm \mathrm{SD}$ & $130.92 \pm 16.97$ & $134.05 \pm 18.36$ & $<0.001$ & $128.04 \pm 21.59$ & $139.77 \pm 21.00$ & $<0.001$ \\
\hline $\mathrm{DBP}(\mathrm{mmHg})$, mean $\pm \mathrm{SD}$ & $80.90 \pm 11.34$ & $82.16 \pm 11.96$ & 0.002 & $73.27 \pm 11.24$ & $77.00 \pm 12.03$ & $<0.001$ \\
\hline Pulse (bpm), mean \pm SD & $76.71 \pm 11.13$ & $77.04 \pm 11.41$ & 0.395 & $79.27 \pm 11.43$ & $77.32 \pm 11.00$ & 0.085 \\
\hline $\operatorname{ALT}(U / L), M_{(P 25-P 75)}$ & $26(20-38)$ & $27(19-38)$ & 0.950 & $19(15-26)$ & $20(14-25)$ & 0.715 \\
\hline$A L P(U / L), M_{(P 25-P 75)}$ & $80(68-95)$ & $82(69-97)$ & 0.056 & $80(64-97)$ & $86.5(71-108)$ & 0.001 \\
\hline Y-GT (U/L), $M_{(P 25-P 75)}$ & $33(23-52)$ & $34(23-56)$ & 0.023 & $18(14-27)$ & $20(15-30)$ & 0.058 \\
\hline TBIL $(\mu \mathrm{mol} / \mathrm{L}), \mathrm{M}_{(\mathrm{P} 25-\mathrm{P} 75)}$ & $14.3(11.5-18)$ & $15.1(12.1-18.8)$ & $<0.001$ & $12(9.6-15.1)$ & $12.6(10.6-15.5)$ & 0.059 \\
\hline GLU (mmol/L), $\mathrm{M}_{(\mathrm{P} 25-\mathrm{P} 75)}$ & $5.3(5-5.9)$ & $5.2(4.9-5.7)$ & $<0.001$ & $5.2(4.9-5.6)$ & $5.3(4.9-6.2)$ & 0.011 \\
\hline $\mathrm{TC}(\mathrm{mmol} / \mathrm{L}), \mathrm{M}_{(\mathrm{P} 25-\mathrm{P} 75)}$ & $5.1(4.5-5.7)$ & $5.1(4.5-5.8)$ & 0.652 & $5.2(4.6-5.8)$ & $5.3(4.6-5.9)$ & 0.395 \\
\hline $\mathrm{TG}(\mathrm{mmol} / \mathrm{L}), \mathrm{M}_{(\mathrm{P} 25-\mathrm{P} 75)}$ & $1.53(1.03-2.29)$ & $1.6(1.11-2.48)$ & 0.011 & $1.13(0.8-1.66)$ & $1.36(0.97-2)$ & 0.003 \\
\hline $\mathrm{HDL-C}(\mathrm{mmol} / \mathrm{L}), \mathrm{M}_{(\mathrm{P} 25-\mathrm{P} 75)}$ & $1.2(1.04-1.4)$ & $1.2(1.06-1.37)$ & 0.775 & $1.44(1.24-1.67)$ & $1.37(1.19-1.55)$ & 0.005 \\
\hline LDL-c (mmol/L), $\mathrm{M}_{(\mathrm{P} 25-\mathrm{P} 75)}$ & $3.08(2.57-3.6)$ & $3.06(2.52-3.58)$ & 0.197 & $3.01(2.51-3.53)$ & $2.99(2.47-3.55)$ & 0.594 \\
\hline Urea (mmol/L), $\mathrm{M}_{(\mathrm{P} 25-\mathrm{P} 75)}$ & $5.4(4.6-6.2)$ & $5.4(4.6-6.3)$ & 0.228 & $4.9(4.1-5.8)$ & $5.3(4.4-6.3)$ & 0.006 \\
\hline $\mathrm{Cr}(\mu \mathrm{mol} / \mathrm{L}), \mathrm{M}_{(\mathrm{P} 25-\mathrm{P} 75)}$ & $72(65-79)$ & $75(68-83)$ & $<0.001$ & $53(48-59)$ & $57.5(52-66)$ & $<0.001$ \\
\hline UA ( $\mu \mathrm{mol} / \mathrm{L}), \mathrm{M}_{(\mathrm{P} 25-\mathrm{P} 75)}$ & $361(312-413)$ & $370(324-429)$ & $<0.001$ & $255(218-301)$ & $290(235-377)$ & $<0.001$ \\
\hline
\end{tabular}

Define low Hcy group (Hcy $\leq 15 \mu \mathrm{mol} / \mathrm{L})$ and high Hcy group (Hcy $>15 \mu \mathrm{mol} / \mathrm{L})$

$\ln$ Hcy $(\beta=0.054, \mathrm{SE}=0.014, P<0.001), \ln C r$ was positively correlated with $\operatorname{lnHcy}(\beta=0.065, \mathrm{SE}=0.006$, $P<0.001$ ), and $\ln U A$ was positively correlated with lnHcy $\quad(\beta=0.069, \quad \mathrm{SE}=0.009, \quad P<0.001)$. For the abnormal Hcy group (Hcy $>15 \mu \mathrm{mol} / \mathrm{L})$, in univariate analysis, lnTC was negatively correlated with lnHcy $(\beta=-0.032, \quad \mathrm{SE}=0.016, \quad P=0.046)$, and $\operatorname{lnHDL}-\mathrm{c}$ was negatively correlated with $\ln$ Hcy $(\beta=-0.060$, $\mathrm{SE}=0.017, P=0.001)$, lnALP is positively correlated with $\operatorname{lnHcy}(\beta=0.062, \mathrm{SE}=0.022, P=0.004)$, and $\ln \mathrm{U}$ rea is negatively correlated with lnHcy $(\beta=-0.045$, $\mathrm{SE}=0.021, P=0.034)$, LnCr was positively correlated with $\operatorname{lnHcy}(\beta=0.065, \mathrm{SE}=0.016, \quad P<0.001)$, and lnUA was positively correlated with $\ln H c y(\beta=0.062$, $\mathrm{SE}=0.020, P=0.002)$. In multivariate analysis, $\operatorname{lnTC}$ was negatively correlated with $\ln H c y(\beta=-0.036$, $\mathrm{SE}=0.016, P=0.027)$, lnHDL-C was negatively correlated with $\operatorname{lnHcy}(\beta=-0.038, \mathrm{SE}=0.016, P=0.019)$, $\ln$ ALP It is positively correlated with $\ln H c y(\beta=0.068$, $\mathrm{SE}=0.022, P=0.002), \ln \mathrm{Cr}$ is positively correlated with $\operatorname{lnHcy}(\beta=0.055, \mathrm{SE}=0.016, P<0.001)$, lnUA and lnHcy were positively correlated $(\beta=0.043, \mathrm{SE}=0.019$, $P=0.022)$. See Table 4 for details.

\section{Logistic regression model analysis of serum Hcy on each index}

The single factor logistic regression model showed that high lnHcy is the occurrence of high TG (OR 1.870, 95\% CI 1.581-2.212, $P<0.001$ ), low HDL-C (OR 1.803, 95\% CI 1.404-2.316, $P<0.001$ ), abnormal $\gamma$-GT (OR $1.270,95 \%$ CI $1.028-1.569, P=0.027$ ), high TBIL (OR 2.456, 95\% CI 1.741-3.464, $P<0.001$ ), high UA (OR 3.106, 95\% CI 2.439-3.956, $P<0.001)$ risk factors. High lnHcy is a protective factor for abnormal ALP (OR 0.692, 95\% CI 0.531-0.900, $P=0.006$ ) and abnormal $\mathrm{Cr}$ (OR 0.737, 95\% CI 0.565-0.960, $P=0.023$ ); multivariate 
Table 4 Analysis of linear regression model of serum Hcy on each index

\begin{tabular}{|c|c|c|c|c|}
\hline & \multicolumn{2}{|c|}{ Single factor analysis } & \multicolumn{2}{|l|}{$\begin{array}{l}\text { Multiple-factor } \\
\text { analysis }\end{array}$} \\
\hline & $\beta(S E)$ & $P$ & $\beta(S E)$ & $P$ \\
\hline \multicolumn{5}{|l|}{ LnTC } \\
\hline InHcy & $0.005(0.007)$ & 0.458 & $0.009(0.007)$ & 0.216 \\
\hline $\begin{array}{l}\text { Hcy (vs. } \\
\text { Hcy } \leq 15 \mu \mathrm{mol} / \mathrm{L} \text { ) }\end{array}$ & $-0.032(0.016)$ & 0.046 & $-0.036(0.016)$ & 0.027 \\
\hline \multicolumn{5}{|l|}{ LnTG } \\
\hline InHcy & $0.212(0.022)$ & $<0.001$ & $0.080(0.021)$ & $<0.001$ \\
\hline $\begin{array}{l}\text { Hcy (vs. } \\
\text { Hcy } \leq 15 \mu \mathrm{mol} / \mathrm{L})\end{array}$ & $0.090(0.049)$ & 0.068 & $0.047(0.047)$ & 0.324 \\
\hline \multicolumn{5}{|l|}{ LnHDL-C } \\
\hline InHcy & -0.087 (0.009) & $<0.001$ & $-0.021(0.008)$ & 0.011 \\
\hline $\begin{array}{l}\text { Hcy (vs. } \\
\text { Hcy } \leq 15 \mu \mathrm{mol} / \mathrm{L} \text { ) }\end{array}$ & $-0.060(0.017)$ & 0.001 & $-0.038(0.016)$ & 0.019 \\
\hline \multicolumn{5}{|l|}{$L n L D L-c$} \\
\hline InHcy & $-0.004(0.010)$ & 0.661 & $-0.014(0.010)$ & 0.169 \\
\hline $\begin{array}{l}\text { Hcy (vs. } \\
\text { Hcy } \leq 15 \mu \mathrm{mol} / \mathrm{L})\end{array}$ & $-0.021(0.023)$ & 0.365 & $-0.034(0.023)$ & 0.140 \\
\hline \multicolumn{5}{|l|}{$\operatorname{LnALT}$} \\
\hline InHcy & $0.079(0.019)$ & $<0.001$ & $-0.053(0.018)$ & 0.003 \\
\hline $\begin{array}{l}\text { Hcy (vs. } \\
\text { Hcy } \leq 15 \mu \mathrm{mol} / \mathrm{L} \text { ) }\end{array}$ & $0.037(0.043)$ & 0.389 & $-0.020(0.041)$ & 0.621 \\
\hline \multicolumn{5}{|l|}{$\operatorname{LnALP}$} \\
\hline InHcy & $0.037(0.010)$ & $<0.001$ & $0.008(0.011)$ & 0.401 \\
\hline $\begin{array}{l}\text { Hcy (vs. } \\
\text { Hcy } \leq 15 \mu \mathrm{mol} / \mathrm{L} \text { ) }\end{array}$ & $0.062(0.022)$ & 0.004 & $0.068(0.022)$ & 0.002 \\
\hline \multicolumn{5}{|l|}{ Lny-GT } \\
\hline InHcy & $0.206(0.025)$ & $<0.001$ & $-0.031(0.023)$ & 0.168 \\
\hline $\begin{array}{l}\text { Hcy (vs. } \\
\text { Hcy } \leq 15 \mu \mathrm{mol} / \mathrm{L})\end{array}$ & $0.072(0.057)$ & 0.210 & $0.036(0.054)$ & 0.503 \\
\hline \multicolumn{5}{|l|}{ LnTBIL } \\
\hline InHcy & $0.122(0.013)$ & $<0.001$ & $0.054(0.014)$ & $<0.001$ \\
\hline $\begin{array}{l}\text { Hcy (vs. } \\
\text { Hcy } \leq 15 \mu \mathrm{mol} / \mathrm{L} \text { ) }\end{array}$ & $0.014(0.030)$ & 0.633 & $0.020(0.030)$ & 0.506 \\
\hline \multicolumn{5}{|l|}{ LnUrea } \\
\hline InHcy & $0.070(0.009)$ & $<0.001$ & $0.017(0.009)$ & 0.058 \\
\hline $\begin{array}{l}\text { Hcy (vs. } \\
\text { Hcy } \leq 15 \mu \mathrm{mol} / \mathrm{L} \text { ) }\end{array}$ & $-0.045(0.021)$ & 0.034 & $-0.030(0.021)$ & 0.159 \\
\hline \multicolumn{5}{|l|}{$\ln C r$} \\
\hline InHcy & $0.177(0.008)$ & $<0.001$ & $0.065(0.006)$ & $<0.001$ \\
\hline $\begin{array}{l}\text { Hcy (vs. } \\
\text { Hcy } \leq 15 \mu \mathrm{mol} / \mathrm{L})\end{array}$ & $0.065(0.016)$ & $<0.001$ & $0.055(0.016)$ & $<0.001$ \\
\hline \multicolumn{5}{|l|}{$\ln \cup A$} \\
\hline InHcy & $0.196(0.010)$ & $<0.001$ & 0.069 (0.009) & $<0.001$ \\
\hline $\begin{array}{l}\text { Hcy (vs. } \\
\text { Hcy } \leq 15 \mu \mathrm{mol} / \mathrm{L})\end{array}$ & $0.062(0.020)$ & 0.002 & $0.043(0.019)$ & 0.022 \\
\hline
\end{tabular}

Multivariate analysis adjusted for age, gender, smoking, drinking, and BMI. LnHcy is the logarithm of Hcy, which is a continuous variable, Hcy is a binary variable, vs. refers to the comparison group, high $\mathrm{Hcy}>15 \mu \mathrm{mol} / \mathrm{L}$ vs. low $\mathrm{Hcy} \leq 15 \mu \mathrm{mol} / \mathrm{L}$ logistic regression model analysis results show that high lnHcy is a risk factor for high TG (OR 1.281, 95\% CI 1.078-1.523, $P=0.005$ ), high UA (OR 2.008, 95\% CI 1.565-2.575, $P<0.001$ ) and abnormal TBIL (OR $1.707,95 \%$ CI $1.205-2.418, P=0.003)$. High lnHcy is a protective factor for abnormal Cr (OR 0.663, 95\% CI $0.508-0.866, P=0.003$ ) and high LDL-c (OR 0.820, 95\% CI 0.699-0.962, $P=0.015)$. For the abnormal Hcy group (Hcy $>15 \mu \mathrm{mol} / \mathrm{L}$ ), single-factor logistic regression showed that high lnHcy is low HDL-C (OR 1.772, 95\% CI 1.184-2.653, $P=0.005$ ), abnormal ALP (OR 1.940, 95\% CI 1.093-3.444, $P=0.024$ ), high UA (OR $1.485,95 \%$ CI 1.052-2.096, $P=0.024)$, abnormal Cr (OR 2.086, 95\% CI 1.271-3.366, $P=0.003$ ) risk factors; multivariate logistic regression analysis results show that high lnHcy is a risk factor for low HDL-C (OR 1.558, 95\% CI 1.017-2.386, $P=0.042$ ), abnormal ALP (OR 1.992, 95\% CI 1.111-3.571, $P=0.021$ ), high UA (OR 1.487, 95\% CI 1.037-2.131, $P=0.031$ ) and abnormal Cr (OR 2.241, 95\% CI 1.364-3.681, $P=0.001)$. See Table 5 for details.

\section{Discussion}

The baseline data collected in this study showed that the smoking and drinking proportion of men was higher. While BMI, SBP, DBP, GLU, Hcy, ALT, $\gamma$-GT, TBIL, TG, LDL-c, Urea, Cr, UA are higher and HDL-C are lower when men compared to women. This may be related to multiple factors such as genetics, lifestyle and eating habits. There is no significant difference in ALP between the two groups, which may be related to the older average age of the subjects we included. Folic acid, vitamin B12, estrogen, etc. in the human body can promote the metabolism of Hcy. Generally, the serum level of Hcy in women is lower than that in men [11-14]. In this study, the average concentration of Hcy was $10.2(8.3-12.8) \mu \mathrm{mol} / \mathrm{L}$, and males were much higher than females. In addition, smoking can indirectly lead to the reduction or lack of folic acid and vitamin B12 levels in the blood and affect the decomposition and metabolism of Hcy [15]. This may also be the reason why the level of Hcy in men is higher than that in women.

From other studies it was found high Hcy related to renal damage [16]. In addition, high UA enhances oxidation and accelerates the production of oxygen free radicals through oxidative stress response, which is ultimately associated with the occurrence and development of cardiovascular and cerebrovascular diseases such as hypertension, coronary atherosclerosis, heart failure and stroke. Many researchers regard UA as an independent risk factor for coronary heart disease. Therefore, in this 
Table 5 Logistic regression model analysis of serum Hcy on each index

\begin{tabular}{|c|c|c|c|c|}
\hline & \multicolumn{2}{|c|}{ Single factor analysis } & \multicolumn{2}{|c|}{ Multiple-factor analysis } \\
\hline & OR $(95 \% \mathrm{Cl})$ & $P$ & OR $(95 \% \mathrm{Cl})$ & $P$ \\
\hline \multicolumn{5}{|l|}{$T G<1.7 \mathrm{mmol} / \mathrm{L}$} \\
\hline InHcy & $1.870(1.581-2.212)$ & $<0.001$ & $1.281(1.078-1.523)$ & 0.005 \\
\hline Hcy (vs. Hcy $\leq 15 \mu \mathrm{mol} / \mathrm{L})$ & $1.285(0.928-1.780)$ & 0.131 & $1.116(0.791-1.573)$ & 0.533 \\
\hline \multicolumn{5}{|l|}{$T C<5.2 \mathrm{mmo} / / \mathrm{L}$} \\
\hline InHcy & $1.054(0.911-1.219)$ & 0.479 & $1.083(0.929-1.263)$ & 0.307 \\
\hline Hcy (vs. Hcy $\leq 15 \mu \mathrm{mol} / \mathrm{L})$ & $0.795(0.573-1.104)$ & 0.171 & $0.743(0.531-1.041)$ & 0.084 \\
\hline \multicolumn{5}{|l|}{$H D L-C>1.0 \mathrm{mmo} / \mathrm{L}$} \\
\hline InHcy & $1.803(1.404-2.316)$ & $<0.001$ & $1.065(0.835-1.359)$ & 0.613 \\
\hline Hcy (vs. Hcy $\leq 15 \mu \mathrm{mol} / \mathrm{L}$ ) & $1.772(1.184-2.653)$ & 0.005 & $1.558(1.017-2.386)$ & 0.042 \\
\hline \multicolumn{5}{|l|}{$L D L-c<3.4 \mathrm{mmol} / \mathrm{L}$} \\
\hline InHcy & $0.905(0.776-1.055)$ & 0.201 & $0.820(0.699-0.962)$ & 0.015 \\
\hline Hcy (vs. Hcy $\leq 15 \mu \mathrm{mol} / \mathrm{L})$ & $0.859(0.603-1.225)$ & 0.401 & $0.819(0.570-1.177)$ & 0.280 \\
\hline \multicolumn{5}{|l|}{$\gamma-G T(10-60 U / L(7-45 \mathrm{U} / \mathrm{L}))$} \\
\hline InHcy & $1.270(1.028-1.569)$ & 0.027 & $0.902(0.729-1.116)$ & 0.343 \\
\hline Hcy (vs. Hcy $\leq 15 \mu \mathrm{mol} / \mathrm{L}$ ) & $1.186(0.808-1.740)$ & 0.384 & $1.108(0.744-1.649)$ & 0.615 \\
\hline \multicolumn{5}{|l|}{ ALT (9-50 U/L (7-40 U/L)) } \\
\hline InHcy & $0.899(0.720-1.123)$ & 0.348 & $0.791(0.627-0.998)$ & 0.048 \\
\hline Hcy (vs. Hcy $\leq 15 \mu \mathrm{mol} / \mathrm{L})$ & $1.411(0.880-2.260)$ & 0.153 & $1.175(0.717-1.924)$ & 0.522 \\
\hline \multicolumn{5}{|l|}{ ALP (45-125 U/L (35-100 U/L)) } \\
\hline InHcy & $0.692(0.531-0.900)$ & 0.006 & $0.726(0.550-0.958)$ & 0.024 \\
\hline Hcy (vs. Hcy $\leq 15 \mu \mathrm{mol} / \mathrm{L}$ ) & $1.940(1.093-3.444)$ & 0.024 & $1.992(1.111-3.571)$ & 0.021 \\
\hline \multicolumn{5}{|l|}{$T B / L \leq 23 \mu \mathrm{mol} / \mathrm{L}$} \\
\hline InHcy & $2.456(1.741-3.464)$ & $<0.001$ & $1.707(1.205-2.418)$ & 0.003 \\
\hline Hcy (vs. Hcy $\leq 15 \mu \mathrm{mol} / \mathrm{L})$ & $1.211(0.736-1.993)$ & 0.452 & $1.241(0.750-2.055)$ & 0.401 \\
\hline \multicolumn{5}{|l|}{ Urea $(3.1-8.8 \mathrm{mmol} / \mathrm{L})$} \\
\hline InHcy & $1.181(0.767-1.817)$ & 0.450 & $1.046(0.675-1.623)$ & 0.839 \\
\hline Hcy (vs. Hcy $\leq 15 \mu \mathrm{mol} / \mathrm{L}$ ) & $0.817(0.367-1.818)$ & 0.620 & $0.963(0.433-2.145)$ & 0.927 \\
\hline \multicolumn{5}{|c|}{$U A(U A \leq 420 \mathrm{umol} / \mathrm{L}(U A \leq 360 \mathrm{umo} / / \mathrm{L}))$} \\
\hline InHcy & $3.106(2.439-3.956)$ & $<0.001$ & $2.008(1.565-2.575)$ & $<0.001$ \\
\hline Hcy (vs. Hcy $\leq 15 \mu \mathrm{mol} / \mathrm{L})$ & $1.485(1.052-2.096)$ & 0.024 & $1.487(1.037-2.131)$ & 0.031 \\
\hline \multicolumn{5}{|c|}{$\operatorname{Cr}(57-97 \mu \mathrm{mol} / \mathrm{L}(41-73 \mu \mathrm{mol} / \mathrm{L}))$} \\
\hline InHcy & $0.737(0.565-0.960)$ & 0.023 & $0.663(0.508-0.866)$ & 0.003 \\
\hline Hcy (vs. Hcy $\leq 15 \mu \mathrm{mol} / \mathrm{L}$ ) & $2.068(1.271-3.366)$ & 0.003 & $2.241(1.364-3.681)$ & 0.001 \\
\hline
\end{tabular}

Multivariate analysis adjusted for age, gender, smoking, drinking, and BMI. LnHcy is the logarithm of Hcy, which is a continuous variable, Hcy is a binary variable, vs. refers to the comparison group, high $\mathrm{Hcy}>15 \mu \mathrm{mol} / \mathrm{L}$ vs. low Hcy $\leq 15 \mu \mathrm{mol} / \mathrm{L}$. The normal reference value ranges of TBIL, Urea, ALP and Cr are indicated by brackets. If there are double brackets, the outer brackets indicate the normal reference value range for men, and the inner brackets indicate the normal reference value range for women. The normal range of $\mathrm{Cr}$ and Urea in parentheses indicates the $20-59$ years old population, the $60-79$ years old population $\mathrm{Cr}$ normal range is (57-111 $\mu \mathrm{mol} / \mathrm{L}$ (41-81 $\mu \mathrm{mol} / \mathrm{L}))$; the $60-79$ year old population Urea's normal range is $(3.6-9.5 \mathrm{mmol} / \mathrm{L}(3.1-8.8 \mathrm{mmol} / \mathrm{L}))$

study, we evaluated $\mathrm{Cr}$ and UA as basic data and found that $\mathrm{Cr}$ and UA in the high-Hcy group were significantly higher than those in the low-Hcy group. Univariate and multivariate analysis of Hcy normal group and abnormal group showed that Hcy was positively correlated with $\mathrm{Cr}$ and UA. In the follow-up study, we will follow up the study subjects to further clarify the relationship between Hcy and kidney injury and other related diseases.
TC, TG, HDL-c, LDL-c are closely related to the occurrence and development of cardiovascular and cerebrovascular diseases. The results of this study showed that the Hcy of abnormal TG and HDL is higher than that of the normal blood lipid group, which is consistent with related literature reports [14, 17]. Some scholars have observed in animal experiments that Hcy injection causes hyperhcy hyperemia, and atherosclerosis occurs 2-3 months later. High levels of Hcy hyperemia 
was considered to be an independent risk factor for atherosclerosis. Studies have shown that elevated levels of mild and moderate Hcy can increase the risk of death from cardiovascular diseases by 4-6 times, and the risk of CHD increases by $60 \%$ in men and $80 \%$ in women for every $5 \mu \mathrm{mol} / \mathrm{L}$ of total plasma Hcy level.

High Hcy can damage blood vessel walls and affect lipid metabolism. In this study, both the univariate and multivariate linear regression model analysis results of Hcy in the normal group showed that Hcy was negatively correlated with HDL-c and positively correlated with TG; while in the high Hcy group, Hcy and HDL-c were still negatively correlated with TC. There is a negative correlation. The existing literature reports that high Hcy is negatively related to HDL-c, but the correlation between TC and TG is not consistent in the literature [17]. This may be related to the source of the research object, the geographical distribution, the degree of fasting before sample collection, the number of samples included in the study, and the factors used for correction in the multivariate analysis.

Hcy is a sulfur-containing amino acid produced during the metabolism of methionine in the body. Its main physiological function is to provide methyl groups for many important physiologically active substances such as DNA, protein and phospholipids in the body. Under normal circumstances, the production and metabolism of Hcy in the body maintain a dynamic balance [18], so that the concentration of Hcy is maintained at $5-15 \mu \mathrm{mol} / \mathrm{L}$ in the blood. There are many factors that affect the level of Hcy. In addition, under certain pathological conditions, taking drugs that interfere with metabolism can affect the metabolism of Hcy. The superoxide and peroxide produced can cause vascular endothelial cell damage and vascular smooth muscle cell proliferation. The structural damage of the wall and the increase of lipid deposits in the blood vessel wall accelerate the process of atherosclerosis. Hcy can also destroy the normal coagulation mechanism, increase the chance of thrombosis, and easily increase the risk of arteriosclerotic diseases such as stroke, coronary heart disease, and peripheral vascular disease. Studies have pointed out that for every $5 \mu \mathrm{mol} / \mathrm{L}$ increase in blood Hcy, the risk of ischemic heart disease increases by $32 \%$, and every $3 \mu \mathrm{mol} / \mathrm{L}$ decrease in Hcy, the risk of disease is reduced by $16 \%$ [19]. A large number of studies have shown that hyperhomocystaenemia is closely related to the occurrence, development and prognosis of a variety of cardiovascular and cerebrovascular diseases, hypertension, diabetes, and kidney diseases [20-22].

There are still some shortcomings in this study. For example, the fasting state of the study subjects may not be completely consistent, and the liver function is not judged in conjunction with imaging, so detailed evaluation was not performed.

\section{Conclusion}

This study shows that Hcy may participate in or affect the metabolism of HDL-c, Cr, UA, etc. The content of Hcy should be paid attention to in clinical work to provide data support for clinical monitoring of cardiovascular and cerebrovascular diseases and renal function.

\section{Abbreviations}

Hcy: Homocysteine; TC: Total cholesterol; TG: Triglycerides; LDL-c: Low-density lipoprotein cholesterol; HDL-c: High-density lipoprotein cholesterol; ALT: Alanine aminotransferase; ALP: Alkaline phosphatase; $\gamma$-GT: $\gamma$-Glutamyltransferase; TBIL: Total bilirubin; GLU: Blood glucose; Cr: Creatinine; UA: Uric acid; BMI: Body mass index; SBP: Systolic blood pressure; DBP: Diastolic blood pressure.

\section{Acknowledgements}

The authors greatly appreciate Prof. Jing Xiao for assistant with statistical analysis.

\section{Authors' contributions}

FB contributed to the conception and design of the study, and participated in the performance of the research, statistical data analysis and interpretation, and drafting and revision of the manuscript. MC participated in the design of the study, performance of the research, statistical data analysis. XS participated in the performance of the research. SJ participated in the performance of revision of the manuscript. HC participated in the performance of the research and revised the manuscript. All authors read and approved the final manuscript.

\section{Funding}

Jiangsu Provincial Funds for Six Categories of Top Talents (Program No. WS-066); The Research project of Jiangsu Provincial Health and Family Planning Commission (Program No. H201526); Nantong Technology Project (Program No. MS12017008-1, MS12020007).

\section{Availability of data and materials}

The datasets used and/or analyzed during the current study are de-identifed and available from the corresponding author on reasonable request. Identifying/confidential patient data should not be shared.

\section{Declarations}

\section{Ethics approval and consent to participate}

This research protocol was approved and exemption from informed consent by the Ethics Committee of Nantong University Affiliated Hospital.

\section{Consent for publication}

Not applicable.

\section{Competing interests}

The authors declare that they have no competing interests.

\section{Author details}

${ }^{1}$ Department of Laboratory Medicine, Affiliated Hospital of Nantong University, Nantong 226001, China. ${ }^{2}$ Department of Blood Transfusion, Affiliated Hospital of Nantong University, Nantong 226001, China.

Received: 29 April 2021 Accepted: 1 September 2021

Published online: 10 September 2021 


\section{References}

1. Nam KW, Kwon HM, Jeong HY, et al. Serum homocysteine level is related to cerebral small vessel disease in a healthy population. Neurology. 2019;92(4):e317-25

2. Cianciolo G, De Pascalis A, Di Lullo L, et al. Folic acid and homocysteine in chronic kidney disease and cardiovascular disease progression: which comes first? Cardiorenal Med. 2017;7(4):255-66.

3. Multi-Disciplinary Expert Task Force on Hyperuricemia and its related disease. Chinese multi-disciplinary consensus on the diagnosis and treatment of hyperuricemia and its related disease. Chin J Intern Med. 2017;56(3):235-48.

4. Zhu J, Gao R, Zhao S, et al. Guidelines for the prevention and treatment of dyslipidemia in adults in China (revised in 2016). Chin Circ J. 2016:31(10):937-52

5. Chinese Diabetes Society. China II guidelines for the prevention and treatment of type 2 diabetes. Chin J Diabetes Mellitus. 2018;10(1):4-64.

6. Dongfeng Gu. Guideline on the assessment and management of cardiovascular risk in China. Chin J Prev Med. 2019:53(1):13-34.

7. Li C, Zhang Y. Considerations on the international hypertension society 2020 International Hypertension Practice Guidelines and hypertension prevention and treatment strategies in China. Chin J Hypertens. 2020;9:815-7.

8. Health industry standard of the People's Republic of China. WS/T 404.12012. http://www.nhc.gov.cn/wjw/s9492/201301/9b2e494990ce482 5a48b4b476f6f928b.shtml.

9. Health industry standard of the People's Republic of China. WS/T 404.42018. http://www.nhc.gov.cn/wjw/s9492/201805/67aa364588f74ec 69a1de85f893ed2c4.shtml.

10. Health industry standard of the People's Republic of China. WS/T 404.52015. http://www.nhc.gov.cn/wjw/s9492/201504/b396412bcbd84e1 ea2b7f9e0e131ae80.shtml.

11. Xu R, Huang F, Wang Y, et al. Gender- and age-related differences in homocysteine concentration: a cross-sectional study of the general population of China. Sci Rep. 2020;10(1):17401.

12. Li X, Yuan J, Han J, et al. Serum levels of homocysteine, vitamin B12 and folate in patients with multiple sclerosis: an updated meta-analysis. Int J Med Sci. 2020;17(6):751-61.
13. Chen Z, Zhang J, Feng J, et al. Higher serum level of Cystatin C: an additional risk factor of CAD. Medicine (Baltimore). 2021;100(2):e24269.

14. Momin M, Jia J, Fan F, et al. Relationship between plasma homocysteine level and lipid profiles in a community-based Chinese population. Lipids Health Dis. 2017:16(1):54

15. Huang S, Cai J, Tian Y. The prognostic value of homocysteine in acute ischemic stroke patients: a systematic review and meta-analysis. Front Syst Neurosci. 2021;14:600582

16. Dervisoglu E, Kozdag G, Etiler N, et al. Association of glomerular filtration rate and inflammation with left ventricular hypertrophy in chronic kidney disease patients. Hippokratia. 2012;16(2):137-42.

17. Mahalle N, Kulkarni MV, Garg MK, et al. Vitamin B12 deficiency and hyperhomocysteinemia as correlates of cardiovascular risk factors in Indian subjects with coronary Artery disease. J Cardiol. 2013;61(4):289-94.

18. Moein S, Vaghari-Tabari M, Qujeq D, et al. Association between serum folate with inflammatory markers, disease clinical activity and serum homocysteine in patients with inflammatory bowel disease. Does folate level have an effect on maintaining clinical remission? Acta Biomed. 2020;91(4):e2020106.

19. Kimball SM, Mirhosseini N, Rankin BD, et al. Retrospective analysis of cardiovascular disease risk parameters in participants of a preventive health and wellness program. Integr Med (Encinitas). 2019;18(3):78-95.

20. Marković-Boras M, Čaušević A, Ćurlin M. A relation of serum homocysteine and uric acid in Bosnian diabetic patients with acute myocardial infarction. J Med Biochem. 2021;40(3):261-9.

21. Li WL, Sang H, Xu X, et al. The correlation study on homocysteine, blood lipids and blood glucose levels in patients with cerebral infarction. Am J Transl Res. 2021;13(5):5659-64.

22. Zhang H, Li Y, Hao M, et al. Kidney function decline is associated with an accelerated increase in plasma homocysteine in older adults: a longitudinal study. Br J Nutr. 2021;24:1-21.

\section{Publisher's Note}

Springer Nature remains neutral with regard to jurisdictional claims in published maps and institutional affiliations.
Ready to submit your research? Choose BMC and benefit from

- fast, convenient online submission

- thorough peer review by experienced researchers in your field

- rapid publication on acceptance

- support for research data, including large and complex data types

- gold Open Access which fosters wider collaboration and increased citations

- maximum visibility for your research: over 100M website views per year

At BMC, research is always in progress.

Learn more biomedcentral.com/submissions 